\title{
Inhibition of protein glycation by phenolic acids: physiological relevance and implication of protein-phenolic interactions
}

\author{
A. Vlassopoulos, M. E. J. Lean and E. Combet \\ Human Nutrition, School of Medicine, College of Medical, Veterinary \& Life Sciences, University of Glasgow, \\ Glasgow, G31 2ER, UK
}

Protein glycation is central to tissue damage occurring as part of the pathogenic process of several non-communicable diseases ${ }^{(1,2)}$. There is a limited body of work on the antiglycative function of (poly)phenols, relying on supra-physiological concentrations and use of non-bioavailable compounds ${ }^{(3,4)}$. To inform the design of a physiologically relevant in-vitro study, a systematic literature review of dietary interventions quantifying plasma phenolic acids was carried out, to inform selection of physiologically relevant concentrations. Bovine Serum Albumin (BSA), either native (no treatment), pre-oxidised (incubated with $10 \mathrm{nM} \mathrm{H}_{2} \mathrm{O}_{2}, 22$ for 8 hours) or incubated with a phenolic acid mixture, for 8 hours) was glycated. Glycation was carried out with i) glucose only $(0,5$, or $10 \mathrm{mM})$, ii) glucose $(0,5$, or $10 \mathrm{mM})$ plus $\mathrm{H} 2 \mathrm{O} 2(10 \mathrm{nM})$, or iii) glucose $(0,5$, or $10 \mathrm{mM})$ plus phenolic acids $(10-160 \mathrm{nM})$. Fructosamine was measured using the nitroblue tetrazolium method. Following (high) dietary polyphenol intake, 3-hydroxyphenylacetic acid is the most abundant phenolic acid in peripheral blood (up to $338 \mu \mathrm{M}$ ) with concentrations for other phenolic acids ranging from $13 \mathrm{nM}-200 \mu \mathrm{M}$. Presence of six phenolic acids with BSA during in-vitro glycation did not lower fructosamine formation. However, when BSA was pre-incubated with phenolic acids, significantly lower concentration of fructosamine was detected under glycoxidative conditions (glucose 5 or $10 \mathrm{mM}$ plus $\mathrm{H} 2 \mathrm{O} 210 \mathrm{nM}$ ) ( $p<0.001$ vs. native BSA). Protein pre-treatment, either with oxidants or phenolic acids, is an important regulator of subsequent glycation in a physiologically relevant system. High quality in-vitro studies under conditions closer to physiology are feasible and should be employed by default.

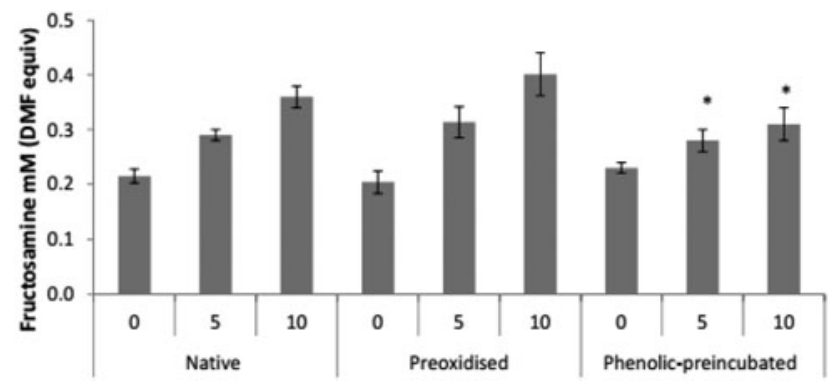

Fig. 1. Fructosamine concentration (mM DMF equivalent) after two weeks incubation in the presence of glucose and $\mathrm{H}_{2} \mathrm{O}_{2}(10 \mathrm{nM})$ for native, pre-oxidised and phenolic-preincubated BSA. Two-way ANOVA analysis showed a significant effect of phenolic-preincubation inhibitin glycation. $* p<0.05$

1. Sabanayagam C, Liew G, Tai ES et al. (2009) Relationship between glycated haemoglobin and microvascular complications: Is there a natural cut-off point for the diagnosis of diabetes? Diabetologia 52, 1279-1289.

2. Yan SF, Ramasamy R, Naka Y et al. (2003) Glycation, inflammation, and RAGE - A scaffold for the macrovascular complications of diabetes and beyond. Circulation Research 93, 1159-1169.

3. Xie Y, Chen X (2013) Structures required of polyphenols for inhibiting advanced glycation end products formation. Current drug metabolism 14, $414-431$.

4. Hou TH, Chung JP, Chen SS et al. (2013) Antioxidation and antiglycation of 95\% ethanolic extracts prepared from the leaves of black nightshade (Solanum nigrum). Food Sci Biotechnol 22, 839-844. 